\title{
Universidad y pensamiento crítico
}

\section{Univesity and critical thinking}

\author{
Julio C. Gambina ${ }^{a}$
}

\begin{abstract}
Resumen
El texto se presenta en cuatro partes. La primera describe el proceso dual y contradictorio de la Universidad como institución del Estado y como movimiento social, que actúa en un contexto histórico. En este sentido se considera el proceso de la Universidad colonial y la reforma universitaria, como el fenómeno de la adecuación de la Universidad a los nuevos tiempos del desarrollo capitalista en el Siglo XX y los desafíos en a actualidad. La segunda parte considera el fenómeno de la mercantilización de los estudios superiores, en sintonía con el sistema de dominación y la privatización de las patentes y los saberes profesionales. En el tercer acápite se consideran las novedades aportadas por el proceso de cambio político a comienzos del Siglo XXI en Nuestramérica y el retraso relativo de la Universidad respecto de la nueva agenda instalada en la región. Finalmente se consideran algunas propuestas para pensar los desafíos del pensamiento crítico en la Universidad.
\end{abstract}

Palabrasclave:universidad, Reforma Universitaria, mercantilización.

\begin{abstract}
Abstrac
The text is presented in four parts. The first describes the dual and contradictory process of the University as an institution of the State and as a social movement, acting in a historical context. In this sense, the process of the colonial university and university reform are considered as the phenomenon of the adaptation of the University to the new times of capitalist development in the 2oth century and the current challenges. The second part considers the phenomenon of commercialization of higher education, in tune with the system of domination and the privatization of patents and professional knowledge. The third section considers the developments brought by the process of political change at the beginning of the 21st Century in our América and the relative delay of the University regarding the new agenda installed in the region. Finally, some proposals to think about the challenges of the critical thinking in the University are considered.
\end{abstract}

Keywords: university, University Reform, commodification.
Kera Yvoty: reflexiones sobre la cuestión social. Vol. 1, 2016, 54-62.

ISSN (impreso): 2519-7797

a Universidad Nacional de Rosario. Argentina,

Fundación de Investigaciones

Sociales y Políticas,

Argentina.

Instituto de Estudios y

Formación de la Central de

Trabajadores de la Argentina

Autónoma, Argentina.

Correspondencia a:

jcgambina@gmail.com

Cita:

Gambina, J. C. (2016).

Universidad y pensamiento

critico. Kera Yvoty: reflexiones

sobre la cuestión social, 1 , 54-62.

Recibido:

25 agosto 2016

Aceptado:

8 octubre 2016 


\section{Introducción}

En lo que sigue se hablará desde mi práctica en la docencia universitaria de grado y posgrado en la Argentina y con alguna experiencia de dictado de clases en posgrados en Brasil, Chile, Colombia, Paraguay; pero también, desde el protagonismo en la militancia estudiantil en los tempranos 70, en la sindicalización docente desde la segunda parte de los 80 (Gambina, 2016a). En rigor, y para ser más amplio, como sujeto partícipe por medio siglo en el debate sobre el papel de la Universidad en la vida cotidiana y la lucha por otra sociedad, en sintonía con demandas de sectores no favorecidos por el orden capitalista.

La Universidad es docencia, investigación y extensión, también metodología de la enseñanza, el estudio y la articulación social, actuando en tiempos concretos en su doble carácter, como institución sistémica y como movimiento social contradictorio. Como institución responde a una tendencia de lógica reproductiva según la demanda hegemónica del orden social, que hace más de cuatro décadas se orienta hacia la extensión de la mercantilización y la iniciativa privada. Como movimiento social asume las contradicciones derivadas de la confrontación entre los proyectos de las clases dominantes y de aquellos sectores sociales con pretensión alternativa.

Con las cuatro décadas remito a la ofensiva capitalista a la salida de la crisis capitalista de los 70, con punto de origen en las dictaduras del Terrorismo de Estado en el Cono Sur de América, que fueran el ensayo para la extensión posterior de las políticas neoliberales en el sistema mundial.

Ambas dimensiones de la Universidad, como "institución" o como "movimiento" presentan contradicciones a su interior, manifestadas en los contenidos y los métodos utilizados para resolver las diferentes funciones (Gambina, 2016b). En algunos casos se han logrado inclusiones institucionalizadas de contenidos y métodos promotores de nuevas agendas para la discusión y así favorecer el pensamiento crítico en la dinámica de la institución Universidad. Es cierto también que a veces, el movimiento universitario replica los modos de la hegemonía, con el burocratismo gremial o la pereza intelectual reproductora de la bibliografía y estudios hegemónicos, eurocéntricos en general, o de origen estadounidense, ocultando o desconociendo el acervo de la producción latinoamericana y caribeña, que es inmenso.

La historia de la Universidad presenta ese carácter dialéctico y en tensión, que entre nosotros, en Nuestra América, se hizo evidente hace casi un siglo con la Reforma Universitaria de 1918. El acontecimiento supuso una ruptura de la forma Universidad y una adecuación de su esencia. La Reforma habilitó el debate sobre el gobierno de la Universidad y su transformación en ámbito masivo de concurrencia estudiantil y su correlato docente y en el área de gestión. En lo esencial, la novedad expresaba a las nuevas clases sociales en la búsqueda de un lugar de poder en la sociedad capitalista.

Para los años previos a 1918, el claustro universitario concentraba a la élite asociada a la hegemonía social que definía un sentido conservador y reaccionario al papel de la Universidad en su contexto histórico de tradición colonial. En todo caso, puede coincidirse que en su seno se formaron personajes que serán activos protagonistas de la lucha política por la independencia del poder colonial, sin que ello supusiera cambios al interior de la Universidad. El desarrollo capitalista a fines del Siglo XIX y comienzos del XX amplió el universo social y con ello a las clases sociales en disputa, lo que se manifestó en la lucha por los signos y símbolos, especialmente, en el ámbito de la generación de la dominación ideológica y teórica: la Universidad. Entre esos signos y símbolos se reconoce a la democracia y los derechos democráticos, lo que puede rastrearse en la afirmación del voto universal y secreto de los varones, mucho más tarde 
de las mujeres, y una serie de instituciones que afirman las demandas democráticas de nuevos sectores sociales que disputan el orden social, político y cultural.

Ese es el contexto de la lucha de los reformistas en la Universidad, en Córdoba, Argentina, y otros países de Nuestra América, que receptaron el movimiento reformista con mayor o menor visibilidad en sus territorios. Se destacan Perú y Cuba', expresando la extensión del movimiento reformista en sintonía con los cambios operados en la producción y en la sociedad de nuestra región. El carácter reformista del fenómeno apuntaba a abrir las puertas de las universidades y terminar con el privilegio de la élite formada en su seno. El orden capitalista en extensión y universalización, producto de los cambios ocurridos a fines del Siglo XIX, salía de la crisis con dominación monopolista y tendencia a la universalización de las relaciones capitalistas y el sistema imperialista. Ese fenómeno extendió la relación capital trabajo y renovó el papel de los Estados nacionales, desarrollando una burocracia que se expandirá ampliamente en los años siguientes. En esa renovación institucional debe fijarse la reforma de la Universidad.

Apuntamos a destacar los cambios en la Universidad en su correspondencia con la situación en la sociedad. El orden colonial dispone de razones e instituciones instrumentales a sus propósitos, que obstaculizan el avance y despliegue empujados por nuevas formas de producción y relaciones sociales generadas por el libre comercio disparado luego de los procesos de independencia política gestados en la región. La Universidad no se adecuó rápidamente al nuevo tiempo de las independencias de los centros coloniales, procesos que vienen cumpliendo dos siglos en nuestro tiempo.

1 Una vertiente reformista anida en el APRA de Haya de la Torre en Perú y otra revolucionaria en Julio Antonio Mella y los orígenes del comunismo en Cuba.
Esas luchas independentistas demandaron pensamientos e innovaciones técnicas y tecnológicas provistas desde la nueva hegemonía mundial, primero de la vieja Europa y luego desde EEUU ya en la primera parte del Siglo XX. Esa demanda define la dependencia tecnológica y del saber científico y técnico en el origen de la inserción subordinada de nuestros países al sistema mundial del capitalismo.

Nuestra América supera el poder colonial con un proceso de subordinación y dependencia al orden capitalista en tiempos de dominación de los monopolios y el imperialismo. Esa perspectiva se orienta a la reproducción del modelo productivo y de desarrollo hegemónico capitalista y consolida la cultura de la sumisión social a la colonialidad de los pueblos originarios indígenas y campesinos y la subordinación a las formas y los modos de la racionalidad de la explotación y la ganancia. Elasunto es más visible en los países andinos que aquellos asociados a la costa atlántica, excepto Paraguay, impedido de su experiencia local ante el accionar reaccionario de la guerra de la Triple Alianza.

La colonialidad del poder y del saber sobrevive en tiempos de la independencia política y se continúa aun con la reforma universitaria, aun cuando, como dijimos al comienzo, la reforma inaugura la tensión al interior de la Universidad, entre el mandato institucional de reproducción social de la explotación y la dominación bajo las condiciones de la Universidad reformada y la lucha al interior del movimiento social universitario para encaminar una perspectiva por la emancipación.

Mencionamos estas contradicciones, preexistentes a la reforma de 1918 y sobrevinientes luego, como expresión de la lucha de clases al interior del pensamiento, que es reproductor o crítico. Ambas realidades tienen vigencia en la tradición universitaria y bien vale la pena recorrer el devenir histórico de las últimas décadas de hegemonía neoliberal para corroborar la correspondencia de la institución 
Universidad con el clima cultural de época por la liberalización. Claro que al mismo tiempo ocurre el pensar críticamente en el seno de la Universidad, en un intento de acercar la Universidad al movimiento popular. En ese sentido cabría mencionar experiencias ocurridas en los 60/70, tanto en procesos institucionales de la Universidad, como en ensayos organizados desde el movimiento popular.

\section{Mercantilización del saber}

La tónica de la evolución de las Universidades en tiempos de neoliberalismo se asocia a la privatización de las empresas públicas, los bienes comunes y por supuesto, de las propias instituciones gestionadas estatalmente, entre ellas, las universidades y la escuela pública en general (Dussel, 2015).

Con la privatización se extiende el papel de la empresa privada, especialmente aquellas de mayor composición orgánica e inserción en la transnacionalización de la economía mundial, como asociados a la Universidad. El financiamiento está vinculado a necesidades de investigación del capital privado y/o a favorecer recursos hacia la docencia o la investigación en las Universidades que legitiman el accionar cotidiano de las empresas, aun cuando estas actúan en el deterioro del medio ambiente y la salud de sus trabajadores o de las poblaciones en que se asientan esas plantas.

Las empresas se apropian del saber específico desarrollado en las Universidades con recursos públicos, para organizarlos detrás de sus propósitos de innovación tecnológica (Lage, 2015). Se financian los nuevos desarrollos, aprovechando capacidad técnica e intelectual financiada por los Estados y sus presupuestos para la educación pública, incluidos los estudios universitarios estatales. Es una práctica que se generaliza desde la propia Universidad, con cátedras, departamentos, facultades y otras formas de organización académica que formulan proyectos de investigación a medida de los financiamientos ofrecidos por las propias empresas o el lobby de organizaciones de cooperación internacional.

Existe una gran sintonía entre las partes para favorecer esas formas de financiamiento, las que actúan sobre los límites de los ingresos de los docentes universitarios. Laprivatización universitaria reditúa para las empresas y las autoridades universitarias que se muestran eficaces a la hora de incrementar presupuestos exiguos que impone el ajuste fiscal derivado de las políticas neoliberales.

La amplitud de los "beneficiados" oculta la trama de la subordinación y la dependencia científica y tecnológica que confirma cotidianamente el sistema de ciencia y tecnología asociado a la Universidad pública. Puede ocurrir incluso, que parte del movimiento social universitario que lucha sindicalmente contra la patronal protagoniza esos mismos procesos de mercantilización y privatización universitaria. Es que los magros ingresos salariales de la docencia y la investigación en la Universidad se completan con fondos de proyectos que involucran a esos mismos docentes o investigadores que protagonizan la lucha sindical y la integración en los procesos de privatización.

Una cuestión de fondo está asociada a la expectativa que genera el acceso a la Universidad con el mercado laboral, especialmente el profesional, en constante mutación. En tiempos de la reforma universitaria el imaginario del graduado universitario apuntaba al ejercicio liberal de la profesión. Los cambios operados en la producción convocan de manera creciente a la contratación de graduados universitarios como trabajadores regulares, e incluso, con la extensión de la precariedad laboral, es un hecho la flexibilización de los contratos de profesionales universitarios. La proletarización de los profesionales universitarios incluye en nuestro tiempo la contratación sin seguridad social, propia 
del trabajo irregularizado por patronales que buscan reducir el costo salarial como parte de la baja del costo de producción.

No todas las profesiones son demandadas en el mercado laboral, por lo cual, la salida laboral actúa también como orientación de la matrícula universitaria. El mercado determina las orientaciones profesionales, con lo cual, la vocación está subordinada a la lógica del empleo y en definitiva del orden económico y social. El caso curioso que siempre destaco con los estudiantes y profesionales de "trabajo social" es el incremento de la demanda de esos profesionales ante las crecientes políticas públicas compensadoras ante la extensión y magnitud de la población empobrecida a causa de la política hegemónica. El trabajo social demanda de profesionales preparados para contener ante la sociedad los problemas derivados de las condiciones económico sociales del capitalismo. El mercado define las características del currículo, la eficiencia y la eficacia de las propias universidades públicas.

Podría también remitirme al crecimiento de la Universidad privada como parte del fenómeno de la mercantilización, en este caso de la escuela y la universidad propiamente dicha. Sin embargo, prefiero concentrarme en la escuela y universidad pública por haber sido el territorio de la reforma universitaria y el ámbito de expresión de la lucha de clases respecto de la formación teórica para los proyectos en pugna.

La mercantilización genera un determinado sujeto social que puebla las universidades, una cultura del ser en la Universidad. Si lo que prima es el mercado, la lógica del dinero y la eficiencia para el régimen del capital, lo que prima en la Universidad es el individualismo exacerbado. La competencia estimula la selección de los "mejores" y con ello los criterios de evaluación que definen quienes son los "mejores". La acumulación de créditos académicos se transforma en recorrido individual para destacarse de otros en la carrera por el ascenso universitario o por ingresos.

Se trata de una conducta que estimula el trabajo a solas más que cualquier cooperación colectiva de difícil ponderación para evaluadores de la eficacia personal en el logro de objetivos a meritar. La "meritocracia" está en el centro de la propuesta mercantil y es el eje del éxito buscado en la aspiración individual del ascenso y el mayor ingreso en dinero que facilite el acceso a la oferta para el consumismo.

Estos cambios que se imponen en la Universidad de la competencia para el mercado están asociados al imaginario que las clases dominantes impusieron en décadas de ofensiva del capital contra el trabajo, los bienes comunes y la sociedad.

Así como las privatizaciones de servicios públicos objetaron al capital público como forma de organización económica de la sociedad, la noción derivada en su conjunto apunta a la negación de la propiedad estatal, colectiva o social y afecta una concepción sobre los bienes comunes de la sociedad, no solo del agua y la tierra, sino y muy especialmente del conocimiento y los saberes.

Eso explica que muchos derechos de la sociedad sean crecientemente concebidos como mercancías que se cambian en el mercado, tal el caso de la salud o la educación, y lleva a debates y luchas internacionales por la desregulación de las patentes y el conocimiento. El objetivo es la privatización del gigantesco incremento de la socialización del conocimiento, precisamente cuando la revolución científica y tecnológica disemina instrumentos tecnológicos que acercan el saber profesional a la sociedad.

Nuevamente nos encontramos ante un desafío deavance social del conocimiento y de una élite del poder global que pretende cercar la diseminación de ese conocimiento social producido contemporáneamente. El desafío pasa por nuevas rondas de rupturas al interior de la Universidad. Quizá una nueva reforma, pero esta vez, no para fundar 
la lógica de recreación social del régimen del capital en tiempos de industrialización dependiente, sino para pensar críticamente el proceso liberalizador.

Puede pensarse en la perspectiva de una nueva matriz productiva articulando pensamiento crítico y Universidad. Las prácticas sociales en la producción, más allá de la lógica mercantil y depredadora de la naturaleza, necesitan ser estudiadas, sistematizadasy reformuladas como política del conjunto social, para desarmar el actual patrón de consumo y su modelo productivo y de desarrollo. Es un mecanismo de la transición hacia otro orden social.

\section{Las novedades sociales para impulsar el pensamiento crítico}

Lo curioso de nuestro tiempo pasa por el acelerado proceso privatizador en las universidades en simultáneo con un proceso de cambio político motorizado a comienzos del Siglo XXI por la dinámica de la lucha de clases en la región Nuestramericana.

Existe un desacople entre el proceso de cambio regional y el papel de la Universidad, que mantiene una perspectiva asociada a la mercantilización neoliberal. Es un asunto a destacar en la realidad Nuestramericana, entre otras cuestiones por una serie de novedades que impuso el movimiento popular en estos años. Entre otras cuestiones destaco: a) las reformas institucionales, cambios constitucionales mediante; b) la innovación en propuestas programáticas superando los rechazos propios de tiempos de resistencia; c) nuevas experiencias de integración alternativa, no subordinada; d) emergencia de sujetos por el cambio social; e) experiencias de protagonismo social en la toma de decisiones habilitando un debate sobre la democracia.

La tesis sustentada es que el movimiento social anticipa cambios que induce al pensamiento crítico y a nuevas síntesis teóricas, que no parecieran ser patrimonio oficial de la Universidad pública, salvo iniciativas no hegemónicas, de cátedras, centros de estudios e investigación, publicaciones no necesariamente institucionalizadas y variadas articulaciones del movimiento popular con ámbitos del movimiento universitario. La colonización universitaria procesada desde la hegemonía neoliberal actúa a la defensiva bloqueando el ingreso de las demandas sociales por transformaciones.

\subsection{Reformas institucionales}

Las constituciones de Venezuela, Bolivia y Ecuador, modificadas entre fines de 1999 y 2009, incorporan institutos del derecho de gran interés intelectual y sin embargo son poco considerados en la academia de la región, tanto en los programas de formación como en los de investigación.

Se trata de la consideración del carácter plurinacional del Estado boliviano y ecuatoriano; la recuperación de la tradición bolivariana inserta en la denominación de Venezuela, lo que supone un debate teórico sobrela tradición indígena originaria campesina y el papel del proyecto independentista de la "patria grande". No es solo consideración jurídica, sino cultural, de reconocimiento a la situación pre colonial y búsqueda de expresión política de mayorías sociales ocultadas por el poder colonial y poscolonial en el marco del desarrollo capitalista.

Una gran novedad apunta a las consideraciones sobre los "derechos de la naturaleza", a contramano de una tendencia positivista sobre los derechos de las personas. Es un punto de vista que coloca a la Naturaleza y a los bienes comunes en una concepción integral más allá del privilegio al ser humano como centro del universo. En tiempos de cambio climático y crisis ambiental derivada del modelo productivo y de desarrollo capitalista, la innovación constitucional a favor de los derechos de los bienes comunes supone un desafío civilizatorio global que debiera ser profundizado en la docencia y la investigación universitaria. 
La cuestión democrática pone en discusión el carácter de la misma en condiciones de desarrollo capitalista, cuando la base de sustentación del orden social tiene origen en la relación de explotación que genera la desigualdad creciente del capitalismo a través de la historia. Más aún la concepción del "vivir bien" en Bolivia, o el "buen vivir" en Ecuador, como paradigmas civilizatorios a contramano de la hegemonía capitalista.

\subsection{Propuestas programáticas}

El cambio político tiene antecedente en la resistencia a las políticas hegemónicas de los años 8o y 9o, los del ajuste y la regresiva reestructuración del capitalismo ocurrida en América Latina y el Caribe, la de las décadas perdidas ${ }^{2}$. Aludimos al NO al ALCA y a los procesos de liberalización, comoal programa porel NO pagodeladeuda externa o el rechazo a la generalización de bases militares.

Desde esa generalización de propuestas por el NO, por el rechazo a la iniciativa del poder, se habilitó un proceso de creatividad popular en la gestación de propuestas por el SI, entre las que destaca la lucha por la soberanía alimentaria. Es una categoría en discusión con la más generalizada de seguridad alimentaria, que sustentan organismos internacionales y el lobby académico que manifiesta la lucha contra la pobreza desde la defensa del modelo agro-alimentario sustentado por las transnacionales de la alimentación y la biotecnología.

La soberanía alimentaria surge como concepción del movimiento campesino y en la lucha de los trabajadores sin tierra que demandan nuevas formas de encarar el desafío por los alimentos de la población.

2 La CEPAL calificó a los 8 o como la década perdida, y si se considera la evolución de los 9o, la historia de la pérdida se repite, más aún si se concibe a la última década del Siglo XX como aquella dominada por las políticas del Consenso de Washington, para la promoción de la privatización, la iniciativa privada y el ajuste fiscal.
Resulta todo un avance teórico y práctico en momentos de grave crisis del orden capitalista, con más de 800 millones de personas en la pobreza según registra la FAO y el crecimiento de la desigualdad.

En el mismo sentido se propone la soberanía energética, lo que supone enfrentar la dependencia tecnológica con las transnacionales del petróleo y generar estudios que involucren a los trabajadores, las universidades y los gobiernos en una política para discutir el derecho a la energía por encima de una tendencia creciente a la mercantilización.

La soberanía financiera fue otra de las iniciativas propositivas gestadas en este tiempo histórico, con los pueblos demandando el manejo soberano de los recursos generados con el trabajo social.

Todas estas propuestas favorecieron la innovación en la discusión por la integración alternativa, al tiempo que definen una perspectiva por la desmercantilización de la vida cotidiana.

\subsection{Integración no subordinada}

Uno de los NO más importantes estuvo concentrado en la campaña continental Noal ALCA, en donde surgieron variadas iniciativas por una integración no subordinada, lo que supone un cúmulo de aportes presentados por el movimiento popular y especialistas.

Salvo excepciones, la Universidad transitó el camino de la aportación a la integración subordinada en la lógica de los sujetos de la dominación: los capitales transnacionales, los principales Estados del capitalismo mundial y especialmente los organismos internacionales, caso del FMI, el Banco Mundial o la OMC que sustentan las propuestas liberalizadoras.

Falta estudiar en nuestras Universidades los avances en nuevos procesos de integración, sus fallos y limitaciones, tanto como los procesos a profundizar para hacer realidad las propuestas soberanas antes mencionadas. Ello constituye un programa a desplegar 
por los estudios universitarios para estar acorde con la demanda de la sociedad.

\subsection{Sujetos sociales y políticos}

Entre otros sujetos visibilizados en el proceso político regional de estos años ubicamos al movimiento indígena originario campesino, con existencia histórica en nuestros países, especialmente en la zona andina, pero in-visibilizados en la lucha por la independencia y la construcción de la inserción subordinada al capitalismo mundial luego de las guerras por la independencia. Las mujeres adquieren una presencia en el presente que favorece la difusión de las reivindicaciones de la lucha por la igualdad de género.

Se trata de la necesaria investigación de los sujetos para el cambio, pero no solo limitado al ámbito de lo político, sino y principalmente en las relaciones económicas, indagando la emergencia de nuevos fenómenos de relaciones económicas y en su despliegue el análisis del sujeto económico por los cambios profundos. Son experiencias de interés para el estudio e involucramiento de la Universidad, el caso de las empresas recuperadas, las mutuales y cooperativas y otras formas de organización económica de la cotidianeidad de los sectores populares.

\subsection{Formas de organización política}

La organización de la vida política requiere ser estudiada ante la crisis política de las formas tradicionales de expresión de la representación política.

En gran parte de la región emergieron nuevos partidos políticos, frentes de partidos o instrumentos electorales, lo que supone una nueva dimensión del mapa de partidos y organizaciones que disputan el Estado en nuestros países.

La crisis de la política hegemónica e histórica se cruza con la ausencia de instrumentos adecuados para expresar la nueva realidad de aquellos que luchan por un cambio social y transformaciones profundas en los territorios de
Nuestramérica.

\section{Algunas consideraciones finales}

La crisis del capitalismo contemporáneo convoca a pensar la transición hacia otra sociedad, superadora, no capitalista y por ende socialista, aprovechando el estudio sobre las experiencias socialistas existentes. Una tarea no realizada despojada de ideologismos y prejuicios anti-socialistas.

Se necesita recuperar la experiencia de la revolución rusa a 100 años de su gestación, y a 25 años de la desaparición de la URSS, para ganar en análisis despojado de falacias ideológicas; del mismo modo que se requiere estudiar el fenómeno de la revolución China y sus modernizaciones recientes desde 1978 y su lugar en el sistema mundial, indagando cuánto hay de transformación o asimilación del orden capitalista. Más aún respecto de la revolución cubana y otros procesos que encararon la perspectiva de la transición del capitalismo al socialismo.

En Nuestramérica resulta indispensable profundizar los pocos estudios sobre esta temática, actualizados con la propuesta del socialismo del siglo XXI formulada por Hugo Chávez a fines del 2004 y comienzos del 2005; o la expresión del socialismo comunitario sustentado en Bolivia por el Vicepresidente Álvaro García Linera en enero del 2010 ante el desafío del segundo mandato del gobierno de Evo Morales; o la actualización del modelo económico del socialismo cubano en 2011, con inspiración de las innovaciones y propuestas que emergieron en nuestros territorios en este tiempo de cambio político.

El pensamiento crítico está desafiado a ganar la hegemonía de la Universidad y derrotar la intervención de la concepción neoliberal que condena a la Universidad a ser funcional a la demanda de las clases dominantes (Quijano, 2014). Un lugar existe para la Universidad en la perspectiva del cambio y eso ocurre en tanto y en 
cuanto la institución y el movimiento en la Universidad articulen con el movimiento popular por el cambio profundo en la búsqueda del tránsito del capitalismo al socialismo.

\section{Referencias Bibliográficas}

Dussel, E. (2015). Razones para aceptar la responsabilidad de ser Rector de la UACM. In E. Dussel (Ed.), Filosofías del Sur. Descolonización y Transmodernidad (pp. 355-365). s.l: Ed. Akal.

Gambina, J. C. (2016a). La Argentina contemporánea y el legado del Che. Manuscrito presentado para su publicación.
Gambina, J. C. (2016b). Marx: la crítica a la Enseñanza Universitaria dela Economía Política. Revista ARGUMENTUM, 8(2), 153-166.

Lage, A. (2015). La economía del conocimiento y el socialismo. Preguntas y respuestas. Recuperadp de http:// www.areitodigital.net/la_economia_ del_conocimiento\%2oLage.htm

Quijano, A. (2014). El regreso del futuro y las cuestiones del conocimiento. Buenos Aires: CLACSO. 